\title{
Adeus, céu azul: a constituição da posição-sujeito imigrante no texto fílmico
}

\section{Goodbye, blue sky: the constitution of the immigrant subject-position in the filmic text}

DOI: $10.28998 / 2317-9945.2019 n 63 p 94-105$

Isaac Costa ${ }^{1}$

\section{Resumo}

Este estudo se filia à linha de Análise de Discurso de inspiração pecheutiana e se propõe a analisar o videoclipe de Céu Azul, tomando como referente a decomposição do texto filmico em niveis descritivos, atravessados por um viés discursivo. Destaca-se que a cidade pode ser tomada como todo significante que se simboliza como lugar discursivo, abrigando posiçoes-sujeito distintas, em relação a um determinado fato bistórico: nesse caso exemplar, a atualização da memória conferida à imigração nos grandes centros urbanos e o consequente acontecimento enunciativo que inaugura a posição de não-abrigado. Discute-se a arte como espaço que valida as posições-sujeito imigrantes, ao deslocar o sentido negativo atribuido ao estrangeiro, cristalizado pela memória social, interpelando-o como artista, em contraposição ao seu público. Provém, neste caso, da FD citadina o discurso em que as duas posições em conflito se inscrevem, sem deixar de serem atravessadas pelo lugar da arte, que interpela o sujeito.

Palavras-chave: Imigrante. Texto fílmico. Análise do discurso

\begin{abstract}
This study, aligned with Michel Pêcheux's Discourse Analysis, proposes to analyze the Céu Azul video clip by means of the decomposition of the filmic text in descriptive levels that are intertwined with a discursive perspective. It is emphasized that the city can be understood as a signifier that symbolizes itself as a discursive place, covering distinct subject positions related to a specific event: in this exemplary case, the updating of the memory ascribed to the immigration in large urban centers the resultant enunciative event that inaugurates the not-obligated position. In this process, the Art is understood as a space that validates the immigrant subjectpositions - displacing the negative sense attributed to the foreigner, which is crystallized in social memory, and interpellates him/ her as an artist in contrast with his/her audience. In this case, the discourse in which the two conflicting positions are inscribed comes from the city's DF, and they are entangled with the place of Art which interpellates the subject.
\end{abstract}

Keywords: Immigrant. Filmic text. Discourse analysis

Recebido em: 10/12/2018.

Aceito em: 18/02/2019.

\footnotetext{
${ }^{1}$ Doutorando em Estudos da Linguagem pela Universidade Federal do Rio Grande do Sul.
} 


\section{Introdução}

O aparato teórico que Pêcheux desenvolve ao propor uma concepção não subjetivista da subjetividade (de natureza psicanalítica), que atravessa e articula a Linguística, o Materialismo Histórico e a Teoria do Discurso, propiciou que a Análise de Discurso (AD) pusesse em contato primados de uma ou outra área, sem necessariamente limitar-se a um direcionamento unilateral ou confundir-se com qualquer uma delas. Essa conjugação encontra tradicionalmente em Linguística aproximações com os postulados saussurianos em especial as noções de língua e de signo (problematizando e deslocando os sentidos cristalizados), e demais grupos integrantes do que se acostumou chamar de núcleo duro da Linguística: mais apropriadamente a Fonética, Fonologia, Sintaxe, Morfologia, Lexicografia e Semântica.

Entendendo que o momento de firmação da Teoria exigia que delimitações muito claras fossem estabelecidas, é plausível que áreas de investigação como a Enunciação, Análise da Conversação, Pragmática, Linguística Textual e Semiótica, para citar algumas, fossem excluídas do cerne de discussões promovidas pela $\mathrm{AD}$, apesar de reconhecidas as suas contribuições para o desenvolvimento de determinadas noções, como, por exemplo, o alargamento do que é entendido como unidade de análise - o texto, tomado em seu sentido mais clássico, que seria a estrutura material em que se manifesta o discurso, o objeto concreto de análise. A tradição tratou de cristalizar o sentido atribuído ao texto como aquele tipográfico, noção que foi expandida pela Análise da Conversação ao considerar o texto verbalizado, linha que também toma corpo na Sociorretórica ao voltar-se para o estudo da oralidade. A semiótica greimasiana, por seu turno, situa o texto como objeto de significação, atribuindo a esta concepção a ideia de planos de expressão, brecha por onde se inscreve o visual. Sob esse crivo, o texto passa a ser entendido como unidade histórica significativa: verbal, visual, ou híbrida - para além do papel e em direção à tela, aos dizeres da rua, à tatuagem, ao corpo, aos gestos, aos silêncios, enfim.

Destarte, a perspectiva aqui adotada é a de conceber material e discursivamente o videoclipe, elencando-o como objeto passível de ser analisado por um dispositivo teórico discursivo, neste caso, aquele de inspiração pecheuxtiana (PÊCHEUX, 1997; 1999), em diálogo com uma base pragmática, de ancoragem semiótica, elucidada por Casetti e Chio (1991). De um lado, são mobilizadas com maior destaque as noções de memória discursiva e de acontecimento enunciativo, conforme formuladas por Pêcheux (1999) e Indursky (2008) respectivamente. De outro lado, figura a conjunção entre o arsenal teórico comumente utilizado na análise de textos como o videoclipe (aí inseridos, também, os longa, média e curta-metragens) e a Análise de Discurso, proveniente dos estudos de Martins de Souza $(2012)^{2}$, ao pensar em níveis de decomposição do texto fílmico atravessados por um viés discursivo que os recompõe.

Essa conjugação referida nos permite pensar em níveis de análise descritivos que vão servir para compreender a complexidade de um objeto que se apresenta composto por uma série de elementos a serem tomados como pontos de referência em conjunto. Não se trata, assim, de estancar na descrição detalhada de cada camada de linguagem presente no texto fílmico, o que representaria, em maior ou menor medida, cair na armadilha da análise de conteúdo criticada por Pêcheux, isenta das determinações históricas essenciais para a compreensão do viés ideológico que se revela pela materialidade discursiva e constitui o

\footnotetext{
${ }^{2}$ Refiro-me tanto ao curso livre Análise Fílmica: uma perspectiva discursiva, ministrado pelo Prof. Dr. Luiz Carlos Martins de Souza (Grupo de Pesquisa em Narrativas, Mídias e Discursividades - FLET/UFAm), nos dias 12 e 13 de setembro na UFRGS, quanto à tese Cartas para quem? O funcionamento discursivo da "falta" no filme Central do Brasil, de autoria do mesmo professor (vide MARTINS DE SOUZA, 2012).
} 
sentido. Longe disso, a intenção é a de lançar um olhar sobre esses pontos de referência que investigue o que eles têm de particular, sem deixar de pensá-los como parte integrante de um todo, universal, que engloba a desnaturalização das relações de evidência produzidas pela Ideologia.

Nesse ensejo, o trabalho do analista compreende uma investigação dos sentidos possíveis que atravesse o imaginário e o simbólico e rume em direção ao apontamento dos reais da Língua (o equívoco), da Historicidade (a contradição) e do Sujeito (a falta), costurados pelo discurso. Esta jornada passa pelo que Pêcheux, em parceria com Fuchs, chamam de "de-superficialização", um gesto que decomponha a superfície material, repensando as estruturas solidificadas e identificando os significados implicados nas suas lacunas, de maneira a revelar que a disposição dos elementos no construto não é aleatória ou um processo completamente consciente e determinado pelo sujeito. No caso do texto fílmico, a de-superficialização, para além do cerceamento da sequência discursiva e sua vinculação à determinada FD, compreende a decomposição em quatro planos, quais sejam:

a) narrativo, primeiro nível de decomposição, engloba a identificação do narrador (quem fala), enredo (o que se fala), tempo e espaço (quando e onde se fala);

b) som-e-imagem-em-movimento, que compreende a disposição dos elementos na cena e o som que os acompanha (no caso do videoclipe, como os objetos e os personagens se comportam em cena e como esse arranjo é casado com a música e/ou com os efeitos sonoros, narrações etc.);

c) representação, que diz respeito à análise da montagem (ordenação dos planos na edição), do enquadramento (a delimitação da imagem) e da mise-en-scène (a encenação propriamente dita); e, finalmente,

d) comunicação, que corresponde à leitura da mensagem posta à interpretação, produzida como sentido evidente.

\section{Um caso}

Essas premissas serão postas em ação a partir da análise da materialidade tomada aqui como objeto: o videoclipe de Céu Aqu $\|^{4}$, canção composta e interpretada pelo cantor paraense Jaloo em parceria com MC Tha, filha de pais baianos, nascida em Tiradentes, ambos agora residentes em São Paulo. O videoclipe acompanha a temática da imigração retratada na letra da música (exposta mais abaixo neste texto), compondo um cenário que recupera a memória dos musicais setentistas da Rede Globo. A leitura inicial é a de que a evolução das personagens durante a narrativa denuncia o lugar de excluído e reflete a jornada do sujeito imigrante por meio da progressão do texto fílmico. Os elementos que integram a narrativa fílmica podem ser interpretados a partir dos níveis de decomposição elencados por Martins de Souza (2012), brevemente apresentados como narrativo, som-e-imagem-em-movimento, representação e comunicação. Esses níveis serão discutidos em compasso com a análise proposta neste estudo, de forma a melhor compreender sua arquitetura e funcionamento.

\footnotetext{
3 A referência é “A propósito da Análise Automática do discurso: atualização e perspectivas”, de 1997 [1975].

${ }^{4}$ Jaloo \& MC Tha. Céu Ažul. Direção de Juily Manghirmalani, Luiz Guilherme Moura e Jaloo, produzido com apoio da São Paulo Film Commission: São Paulo, 2018. Disponível em <https://goo.gl/Z7pxd4>. Acesso em: 26 fev. 2019.
} 
Ao primeiro desses níveis, o narrativo, podemos associar as categorias de pessoa logicamente pressupostas na narrativa. Notadamente, há um tu a quem um eu se dirige, o que se traduz como enunciatário (sujeito-expectador) e enunciador, o sujeito-autor, no sentido a ele atribuído enquanto categoria que estanca a passagem do interdiscurso para o intradiscurso. Cabe, assim, ao autor, um efeito de fecho, de acabamento, de ser a figura que organiza a narrativa e que responde por ela. Interessa destacar que o funcionamento dessas duas categorias, encarado como logicamente pressuposto, produz um efeito de associação imediata entre sujeito-autor e quem canta/quem diz, ao passo em que o tu estaria em paridade comigo, a figura que interpreta, a projeção do enunciatário como eu a quem se busca atingir.

Este ato primeiro de identificação do sujeito-expectador envolve a validação/aceitação do produto organizado pelo sujeito-autor. Existe aí a necessidade de identificar-se, contra-identificar-se ou desidentificar-se com os saberes produzidos pelo discurso veiculados pelo material. Na contramão desse processo, situa-se a relação virtual do sujeito-autor com seu expectador, que idealiza essa figura enquanto correspondente imaginário que aceite o que se diz/produz. Note-se que, nesse jogo de projeções, estão imbricados, de um lado, cantores, diretores, roteiristas, e o material com efeito de fechamento apresentado como mensagem final e, de outro, os espectadores e seu trabalho de interpretação. De maneira a organizar essa relação, equipararemos a gama de funções e lugares sociais a que corresponde o sujeito-autor aos artistas, e a trama complexa que diz respeito ao sujeito-expectador ao seu público.

De uma perspectiva distinta da díade artista/público, e ainda no que diz respeito ao primeiro nível de decomposição, no interior da narrativa instauram-se duas figuras em diálogo, um eu explícito no enunciado, um narrador, que se refere a um tu igualmente explícito, um narratário. No caso de Céu Azul, as duas figuras são marcadas já no primeiro verso "Hoje en que finjo que você não existe", reservando-se ao "eu" a identificação do narrador, e ao "você" o espaço do narratário. O diálogo prossegue na letra da canção em formas cristalizadas pelo pronome pessoal oblíquo "mim", relativo ao narrador, e pelo possessivo "seu", condizente ao narratário. As colocações associadas ao narrador equiparam o pessoal com o obliquo, por definição: aquele que não é linear, torto, sinuoso, indireto, inclinado, sintoma do que acredito ser a posição-sujeito desse narrador: a do imigrante, não pertencente. Em oposição, o narratário é retomado com um pronome possessivo, que expressa a vontade de possuir algo ou alguém, egoísta, mesquinho, o outro dessa posição-sujeito imigrante que enxerga o habitante da grande cidade como perverso, aquele que trata do estrangeiro como exótico, olhando-o "com cara enjoada de fotografia", conforme a letra da canção que acompanha o clipe:

[Verso: Jaloo] Hoje eu que finjo que você não existe / Se soubesse de onde eu vim, não me sorria / No oposto do sol encontrei o meu posto / E te queimei com meus raios em grande quantia [Verso 2] Que engraçado que me olha assim / Com cara enjoada de fotografia / Agora que sabe, tem medo de mim / Mas no seu lugar eu também teria / Queria escrever uma bela canção / Mas faltou caneta, faltou papel / Tudo que eu tinha era papel de pão / E um único blues, o pedaço de céu [Refrão: Jaloo] Adeus, céu azul / Mundo em descomunhão / Eu vou pra essa cidade / Pra perto do tal do ego bom / Adeus, adeus céu azul / Não rasga a pele / Fere o coração / Me dê intimidade / Pra deitar e sonhar no teu chão [Verso 1: MC Tha] Hoje eu que finjo que você não existe / Se soubesse de onde eu vim, não me sorria / No oposto do sol encontrei o meu posto / E te queimei com meus raios em grande quantia [Verso 2: MC Tha] Que engraçado que me olha assim / Com cara enjoada de fotografia / Agora 
que sabe, tem medo de mim / Mas no seu lugar eu também teria / Queria escrever uma bela canção / Mas faltou caneta, faltou papel / Tudo que eu tinha era papel de pão / E um único blues, o pedaço de céu [Refrão: Jaloo e MC Tha] / [Outro: Jaloo e MC Tha] Vou avisar / Vou avisar aos cachorros da rua / Que a minha ferida crua é melhor não lamber / Vou avisar / Vou avisar aos cachorros da rua / Que pro povo pobre, a vingança pode ser mel e prazer (JALOO; MC THA, 2018, s/p).

Apresentação de Jaloo [por MC Tha] É o meu choro fácil / laço que foi dado em outra vida / é o meu abraço que carrega / o medo de soltar e sumir no mundo / Jaloo é cavaleiro, caboclo elegante / cuja arma é uma flecha / que voa firme e acerta o alvo / é a mata que a todo tempo produz / é o melhor do amor de Oxum. Apresentaşão de MC Tha [por Jaloo] Tha é um precipício se fechando / uma prisão se abrindo / é o dia começando / magia e sossego / desespero de vida / a Tha é a minha preferida / é luz e paz / esperança e elegância / o findar de toda andança / é MC Tha. (JALOO; MC THA, 2018, s/p).

Perceba-se, neste ponto, que as duas posições-sujeito que começam a ser cerceadas parecem integrar um mesmo espaço discursivo, já que reagem, ainda que de maneiras distintas, a um mesmo fato histórico: a imigração. No cenário de Céu Azul, a imigração enquanto fato resgata uma memória cristalizada, não cognitiva ou recuperada individualmente, mas social, resultado do enlace entre a memória mítica, a memória inscrita nas práticas sociais, e a memória construída do historiador, uma memória discursiva, nos termos de Pêcheux (1999, p. 49). Esta é a memória da imigração dos povos do norte e nordeste do país para os grandes centros urbanos, cuja maior expressão ocorreu entre os anos $1960 \mathrm{e}$ 1980. Cabe aí, ainda, uma atualização dessa memória que repousa na releitura que é construída pela arte e que permite que o imigrante seja visto como atração, pluralidade, novidade, representante de uma subcultura específica, agora valorizada. Esse imigrante, assim, recebe diferentes apreciações a depender do lugar que ocupa na grande cidade: se nas forças de produção (negativo) ou no trabalho artístico (positivo).

De toda sorte, em nenhum dos dois lugares anteriormente referidos, essa posição imigrante será tomada como parte integrante da hegemonia, representada, nesse caso, pela posição-sujeito residente. Essa relação conflituosa entre a classe representante da hegemonia (residente), e a contra hegemônica (imigrante) vai se traduzir como interdependente em Céu Azul, em que se inscrevem enunciador e enunciatário no discurso da arte assumindo os lugares aludidos de artista e seu público. A tessitura da toile de fond do videoclipe, que reforça essa ideia de que o espaço reservado para o imigrante é o do estranho, ainda que ele opere como artista, o apreciado, aplaudido, reconhecido, recupera a memória do menosprezado, do posto de escanteio, do não-integrante que foi subjugado nos espaços sociais por onde circulou, e que se reserva ao direito de só existir em nicho, sustentado pela memória do exótico associada à arte. Para sustentar essa leitura, é necessário perpassar por outros elementos constituintes do nível narrativo investigado por Martins de Souza, tais como o enredo, as personagens, o espaço e o tempo, eixos explorados a partir deste ponto.

A cisão que opera Martins de Souza (2012), ao delinear os quatro níveis fundamentais de decomposição do texto fílmico e seus subitens, comporta em si o fato de que os limites entre uma camada de linguagem e outra, por vezes, se condensam, de maneira que a leitura realizada consubstancia elementos distintos. É o que acontece, por exemplo, na conexão entre o som e a imagem-em-movimento: no caso do videoclipe, a canção e o ato de cantá-la, o que se dá, também, pela corporificação das personagens (quem canta). Assim, o que se ouve no vídeo é, efetivamente, a música, a não ser pelas cenas em que ocorre a introdução de uma personagem, ou a passagem de uma personagem a outra, ato que se marca pela 
narração descritiva das características de quem são essas personas. Na mesma medida, quem se vê como imagem-em-movimento no vídeo são as personagens, postas em paridade com o narrador, já que também são elas que efetuam o ato descritivo de apresentar quem canta. Para representar o dito, detenhamo-nos na leitura das sequências discursivas reunidas, compostas por frames organizados em linha, da esquerda para a direita, e separados por um espaço em branco. Correspondem, assim, às sequências 1 e 2 , as duas primeiras linhas de recorte dispostas abaixo.

\section{I - Sequências 1 e 2}
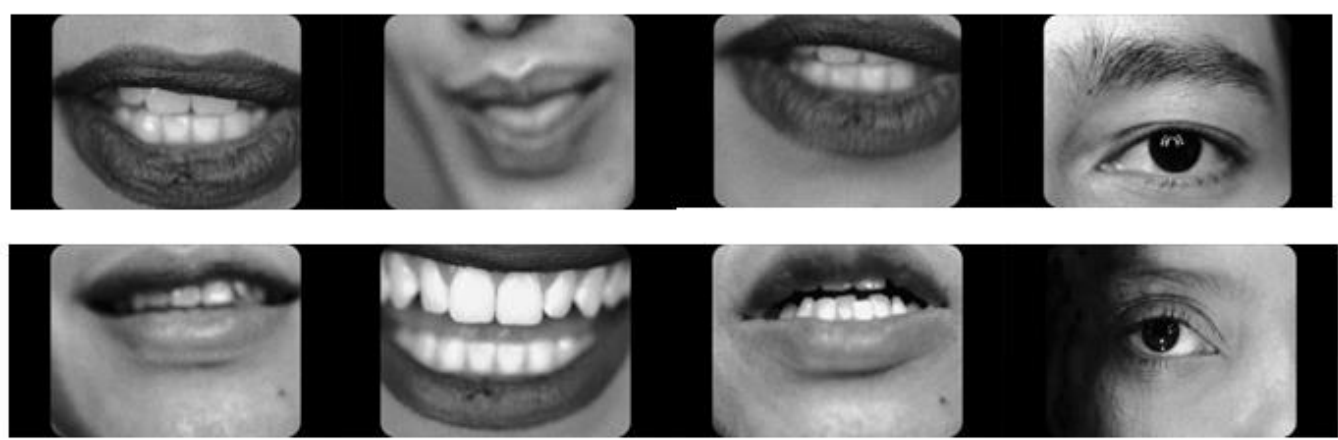

Fonte: Jaloo; MC Tha, 2018.

A imbricação desses aspectos continua a acontecer entre as personagens e a maneira como ocorre sua representação: em cena, cantando, com microfones em mãos. Interessa destacar, nesse entremeio, as diferenças que existem no eixo da representação no que diz respeito à referida introdução das personagens. $\mathrm{Na}$ apresentação, o plano é o de detalhe (ou corta para o de detalhe, precedido de fade, como é o caso da introdução de MC Tha por Jaloo em $01 \mathrm{~m} 47 \mathrm{~s}$ ) em partes específicas do rosto dos cantores que vão sendo postas em contato e remontando uma face completa na medida em que a descrição sobre eles avança.

O plano, ainda em detalhe, situa um interlocutor que articula as palavras com o movimento da boca, estanque, apresentando um interlocutário que vai sendo construído pela conjunção entre boca, olhos e nariz. Esse interlocutário, entretanto, não chega a ter o rosto completo mostrado em um plano mais aberto na apresentação, por exemplo; do detalhe, característico desse momento de apresentação, sempre em preto e branco, esse plano passa para um plano americano ou médio, já marcado pelo ato de cantar, em cores, situando a passagem de interlocutário para Narrador A (imbricação atribuída ao personagem Jaloo) ou Narrador B (imbricação atribuída ao personagem MC Tha). O conjunto plano detalhe + preto e branco divide, assim, interlúdios (onde se apresentam as personagens sem cor, sem vida, ainda no processo de subjetivar-se) e espetáculo (onde a validação da personagem como narrador se efetiva, as várias cores, a vida, inscrição do sujeito propiciada pela arte).

A memória que aí se recupera dialoga com a composição imagética presente nas aberturas dos musicais das décadas de 1970 e 1980 exibidos pela Rede Globo de televisão, dentre os quais figuram o programa Concertos para a Juventude, televisionado até 1984, e os videoclipes produzidos pelo Fantástico, que seguiam as mesmas determinações estéticas. $\mathrm{Na}$ sequência destacada, o plano detalhe que apresentava os instrumentos em preto e branco enquanto as legendas eram inseridas é a referência explícita utilizada pelo sujeito-autor em Cén Azul. É por esse viés que podemos compreender o espaço disposto no videoclipe - o palco televisionado, um concerto ensaiado para ser exibido a posteriori, sem público imediato, que apesar de emitir o barulho de aplausos no início do clipe, o faz de maneira dissimulada, over, fora do plano, da cena, do que efetivamente ocorre e é visto; nessas condições, hoje é o narrador aquele "que finge que você não existe". 
II - Sequências 3, 4 e 5.
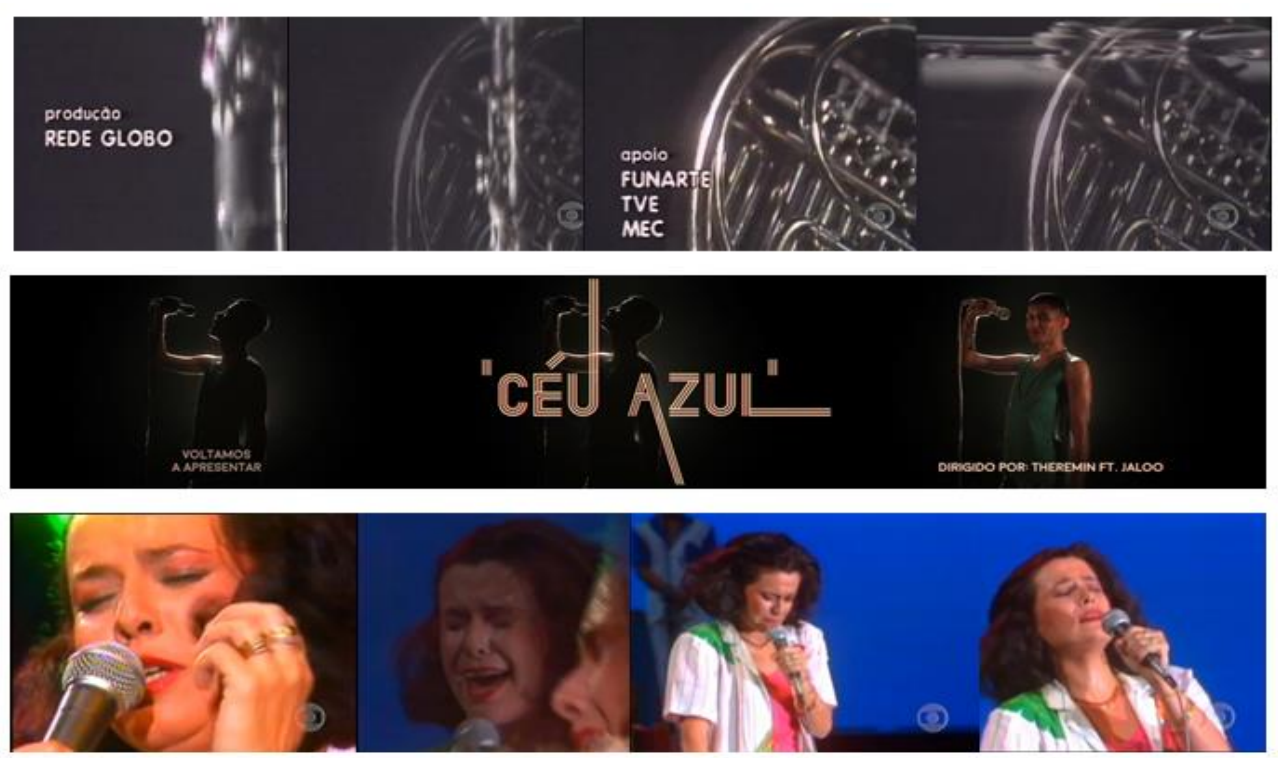

Fonte: Globo, 2018; Jaloo; MC Tha, 2018.

Outro ponto de encontro que revela essa memória referente aos concertos setentistas da rede Globo e a ambientação de Céu Azul é a transição por fade (sequências 5 e 6), um esmiuçamento sutil da imagem anterior que fica sobreposta até que seja completamente dissolvida na posterior. A técnica é largamente utilizada para indicar passagens mais calmas de um frame a outro, como ilustrada na sequência 5, extraída da performance de Atrás da Porta, interpretada por Elis Regina e exibida pela Globo em 1979 - um clipe de narrativa dramática e de passagens sutis em fade in e out. A esse sentido de passagem gradativa, mansa, proporcionado pelo fade, pode-se acrescentar o fato de que a progressão do enredo da narrativa de Céu Azuul, que acompanha a letra da canção, é marcada pela repetição de fades até a quebra da sequência pelo corte $(03 \mathrm{~m} 13 \mathrm{~s}$ e $03 \mathrm{~m} 39 \mathrm{~s})$, posicionado nas partes em que os narradores dirigem-se diretamente ao narratário ("vou avisar aos cachorros da rua que a minha ferida crua é melhor não lamber"), reservando-se as passagens sutis exclusivamente para quando interagem entre si (02m50s; $03 \mathrm{~m} 25$ e $03 \mathrm{~m} 32 \mathrm{~s})$.

Este último efeito de sentido de evolução gradual é reforçado pela montagem, da ordem da representação, e que acentua o percurso percorrido pelas personagens ao marcar um desenvolvimento na caracterização dos cantores pela roupa que vestem - simples no início do vídeo, um pouco mais elaborada no meio, e luxuosa no final (sequência 7). Esta jornada está em consonância com aquilo que é próprio do plano da comunicação: a veiculação da canção, que aponta para um narrador que ascende na medida em que deixa o lugar de onde provem - "adeus, céu ąul", e segue em direção a "essa cidade", pra "perto do tal do ego bom".

Apesar dessa ascensão, essa posição-sujeito imigrante validada pela arte não participa da economia de maneira efetiva, o que se evidencia pelo "voltamos a apresentar" (sequência 4) no início do clipe, marca linguística que carrega a memória de um programa que "voltou dos comerciais". Esse distanciamento da propaganda comercial, uma das principais fontes de renda da emissora televisiva, afasta a posição-sujeito tanto do lugar que produz, quanto do que divulga e daquele que recebe pela produção/divulgação. $O$ espaço reservado à ascensão pela arte não é, assim, financeiro; não participa dos meios de produção, mas fica à margem deles.

Para além da estrutura base elucidada pelo plano da comunicação, esse narrador denuncia a angústia sentida ao deixar a terra natal, o que se pode verificar no seu "mundo em 
descomunhão", e em passagens que dramatizam o corte da relação com o lugar de origem, que "não rasga a pele", já que não é físico, mas que "fere o coração". O enredo engloba, assim, a saída desse sujeito do espaço que lhe é próprio para outro mais ríspido, no "oposto do sol", uma cidade grande que permite que o "ego", o apreço exagerado por si próprio, a busca pelo sucesso individual, seja "bom”, permitido, ao contrário dos espaços comunitários e pequenos grupos em cidades do interior, que o egoísmo seja aceito como positivo.

No caminho do desenvolvimento do ego, nessa busca pela ascensão social, o sujeito vai delimitando o seu lugar de oposição a um grupo que "se soubesse de onde vim, não me sorria", deixando marcada a rejeição do residente pelo imigrante. A mesma rejeição é retomada, ainda que com um tom mais passivo-agressivo, em sequências como "Hoje eu que finjo que você não existe", que pressupõe uma realidade passada ao advérbio "hoje" - ontem, outrora, em que o residente (você) finge que o imigrante (eu) não existe, apagando, segregando ou silenciando essa posição em determinados espaços. A inversão desse papel, neste interim, o jogo entre os pronomes pessoais e a relação deles com o advérbio de tempo (boje, ao contrário de ontem, sou eu e não você quem esnoba), revela que na jornada desse sujeito-imigrante está implicada uma ressignificação proporcionada pela Arte, mais especificamente, a referida atualização da memória da imigração pela sua relação com a arte, o espaço onde se é permitida a existência do exótico sob o aval da licença poética, da multiculturalidade.

\section{III - Sequências 6 e 7}
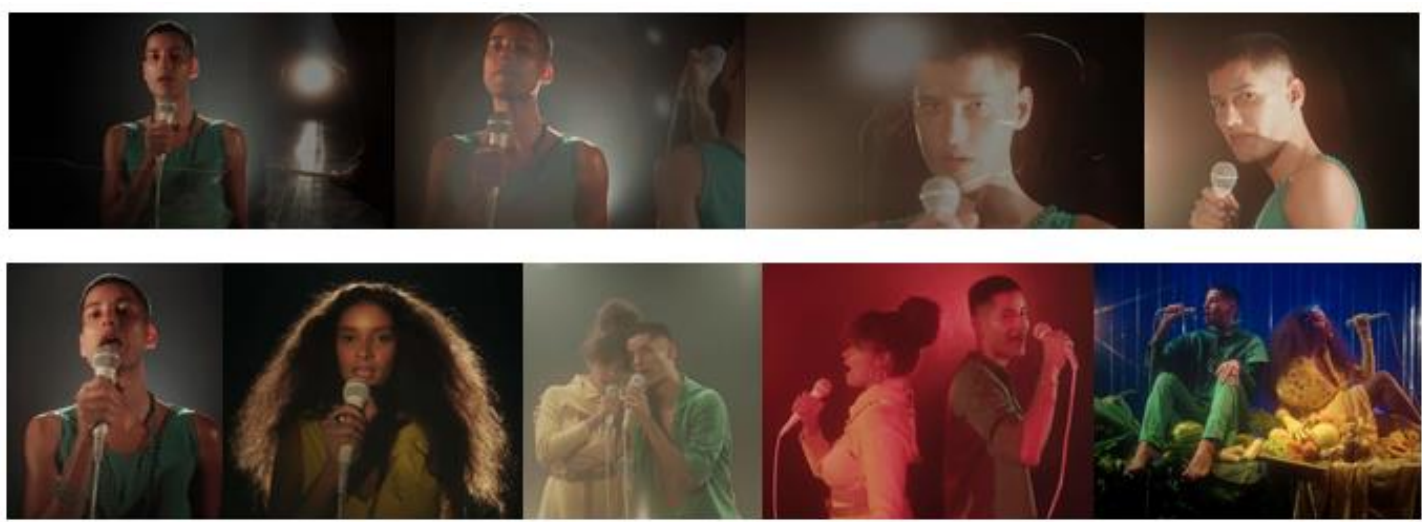

Fonte: Jaloo; MC Tha, 2018.

Nessas vias, fora do discurso da arte, que desloca a carga negativa atribuída ao imigrante, ressignificando-a como "autêntico/multicultural/culturalmente diverso", e em direção ao discurso explicitamente político, por exemplo, a ocupação da posição-imigrante é tomada como invasão pelo residente. Essa posição de exclusão é ainda mais fortemente marcada se esse imigrante carrega carga cultural do norte e/ou nordeste do país, como pode se verificar em episódios como o rechaçamento dos nordestinos nas eleições de $2014^{5}$, por exemplo.

A memória que daí advém recupera a ocupação dos espaços urbanos por essa população que massivamente migra para o estado de São Paulo e outras regiões do sudeste para servir de mão-de-obra a partir da década de 1930, mas mais expressivamente entre 1960 e 1980, época em que Céu Aqul se ambienta. Por trás das grandes máquinas e nas lavanderias das casas dos donos do maquinário, a esse povo não era conferido o espaço da agência intelectual, segregação que alimenta uma ideologia que, por sua vez, finca raízes na cultura e

\footnotetext{
${ }^{5}$ Episódio abordado em diversas matérias jornalísticas veiculadas antes e depois da vitória de Dilma Rousseff em 2014, disponíveis no site do Terra <https://goo.gl/Gj1LEf>, GGN < https://goo.gl/63k2EB>, Veja <https://goo.gl/Yn214k>, e UOL < https://goo.gl/Vo6ty3>, para citar alguns. Acesso em: 26 fev. 2019.
} 
que se mantem latente, revestida por esse ou aquele discurso, revelada sob os mais diversos equívocos de tempos em tempos.

A jornada de ascensão desse narrador, proporcionada pela conjuntura sócio-histórica e política, permite que sua posição seja validada no interior de certa esfera de atuação e excluída de outra, processo que não se dá de maneira isenta de resistência. Esse lugar não é aceito de bom-grado, movimento que se evidencia pela marcação contrária da posição-sujeito imigrante aos saberes que circulam no espaço significante da formação discursiva que aí se delineia - uma FD citadina que apresenta como dominante a posição de pertencimento à cidade.

Essa cidade é tomada aqui em sua expressão simbólica de espaço cerceado a ser preenchido, ocupado pelos residentes. Esta residência não é de forma alguma homogênea: a cidade comporta seus moradores, mas não os põe em pé de igualdade, na medida em que os organiza nas vias em que lhe permite a expressão da formação social, que é, em si, heterogênea e conflituosa, constituída pela disputa entre o público e o privado, o arborizado e o concreto, o tachado e o pichado, o imigrante e o natural, enfim. Esse espaço caracterizado pelo efeito ilusório de todo, abriga o não-todo: lugar que permite expressões materiais heterogêneas reunidas sob o mesmo signo do urbano - um espaço discursivo intervalar, se aqui é possível um paralelo com Grigoletto (2005).

Para além das condições de produção fornecidas pela formação discursiva citadina e em direção ao referido acontecimento enunciativo que situa a atualização da memória da imigração pela arte, figura esse ato de resistência do sujeito que, apesar de morar nessa cidade, não a reside, com ela não tem "intimidade pra deitar e sonbar no teu chão", de maneira que o lugar do diferente, do "oposto do sol", não é apagado. A latência dessa diferença que carrega o sujeito que é, contraditoriamente, abrigado, mas não pertencente, permite pensar em uma agitação nos saberes emanados pela forma-sujeito que organiza a FD citadina.

Nesses moldes, diferente de se pensar no residente e no não-residente, deparamonos com o residente e o estranho abrigado, que promove uma movimentação intensa nos processos discursivos dessa FD. Esse agitamento, nesse caso em específico, não chega a configurar uma ruptura com os sentidos que emanam da FD e o consequente surgimento de nova Formação Discursiva e Forma-Sujeito (ao que se poderia associar um acontecimento discursivo), mas, certamente, esse movimento remete a uma nova posição-sujeito no interior da FD citadina, ao que se pode conferir a designação de um acontecimento enunciativo, conforme nos permite formular Indursky (2008): a marcação de uma posição-sujeito imigrante, abarcada pela FD citadina, ainda que de modo a deixar explícito esse seu pertencimento na exclusão.

Essa posição-imigrante que pertence rejeitando a cidade é assim delineada sob dois eixos: de um lado, a falta da cidade natal e a consequente rejeição à cidade nova; e de outro, o ataque ao sujeito-residente e a consequente afirmação como diferente. No primeiro desses vieses podem ser agrupadas sequências como "adeus, céu azup", "de onde eu vim", e "Fere o coração", indicativas da dor ocasionada pela falta e identificadoras da origem, ao passo que "oposto do sol", "Mundo em descomunhão", e "essa cidade" caracterizam uma cidade impessoal e distante, "essa" em lugar de "esta", que está mais para o chão que para o céu: "me dê [céu, lugar de origem] intimidade [permissão para circular, para agir naquele espaço] par deitar e sonhar no teu chão [cidade, novo espaço duro, sem sol]", o que é metaforizado, no plano da representação, pelos pés sempre descalços das personagens e seu contato direto com o chão duro/frio. 
No segundo desses eixos, circulam o deboche "Que engraçado que me olha assim / com cara enjoada de fotografia", e a ameaça "Agora que sabe, tem medo de mim / Mas no seu lugar eu também teria", que marcam o ataque ao sujeito-residente, na medida em que "Hoje en que finjo que você não existe", e "te queimei com meus raios em grande quantia", apontam para uma afirmação do imigrante como diferente e, não obstante, como figura que vinga, que afronta, que vira o jogo e ascende socialmente apesar das faltas e das pressões do "ego bom" e de suas limitações "Queria escrever uma bela canção / Mas faltou caneta, faltou papel / Tudo que eu tinha era papel de pão". Essa nuance particular da posição-imigrante é sustentada no plano da representação pela evolução do figurino, indicativa da jornada de ascensão, pela agressão que carrega o corte em detrimento do fade nas transições de frame, e pela cor do fundo da cena (sequência 7), que perpassa pelo branco (na narrativa, o momento em que as personagens conseguem equipararse em força [mas não em poder] à posição sujeito-residente), muda para o vermelho (a fraternidade entre as personagens e a violência delas para com a posição-residente) e finda com o azul (a frieza, a sensação de liberdade) ${ }^{6}$.

Ressalte-se também que a composição das cores do figurino, como verde para o personagem de Jaloo e amarelo para a personagem de MC Tha, carrega consigo os sentidos cristalizados pela memória de que o verde simboliza a mata, e o amarelo, o ouro, o que pode apontar para a delimitação dos lugares de onde discursivisam os enunciadores: o Pará (a segunda maior porção remanescente de Mata Atlântica), e a cidade de Tiradentes (a figura do minerador). Além disso, verde e amarelo são as cores que junto com o azul, que aparece tanto no título do videoclipe quanto no fundo representado na última cena, compõem a bandeira do Brasil, aproximando as personagens desse efeito metonímico de serem tomadas como retrato desse povo.

A ideia de povo também é aludida na última estrofe da canção, na construção " $V o u$ avisar aos cachorros da rua / Que a minha ferida crua é melhor não lamber / Vou avisar aos cachorros da rua / Que pro povo pobre, a vingança pode ser mel e prazer", sequência que equipara o narrador aos cachorros da rua, já que ele fala a língua deles, e que identifica, por consequência, a posiçãosujeito imigrante à de cachorro. O cachorro que passa pelas ruas sem dono, que causa incômodo, que precisa ser recolhido, tratado como sujo, aquele que por mais que seja adotado e sirva de bicho de estimação, não tem raça, nem ocupa lugar de poder na família. Ao falar para seu povo, o narrador diz não precisar da piedade dos iguais, metaforizada pela lambida, sinal de afetividade entre os cães. Essas feridas abertas pela falta do céu que lhe feriram o coração, "é melhor não lamber": não se precisa de caridade, em sentido à deriva, é preciso que os outros cachorros tenham cuidado para que, ao lamberem, não se sejam acometidos pelo mesmo mal - o de corromper-se pelo germe do egoísmo e deixar seu pedaço de céu.

Assim também, outro recado para os demais cachorros é que "para o povo pobre, a vinganç pode ser mel e prazer", o que aponta para o conflito entre aquele colocado de escanteio, o imigrante, e o representante da hegemonia, o residente, agora em condições de servir de alvo para a indiferença do imigrante. Ressalte-se aqui que esse lugar de retorno que põe o sujeito oprimido em condições de exercer qualquer vingança é validado apenas nos espaços em que se permite que ele atue: a ideia de que o oprimido toma o poder e se mantém na situação de oprimido é pífia, já que o poder se exerce sobre algo ou alguém, oprimindo-o, tomando-se, assim, o lugar de opressor. Destarte, como essa posição-imigrante não encontra

\footnotetext{
${ }^{6}$ A referência é à memória social de que o azul está para a liberdade, o branco para a igualdade e o vermelho para a fraternidade, em diálogo com o Liberté, Egalité, Fraternité, lema da Revolução Francesa, em relação às cores da bandeira da França (azul, branco e vermelho, nesta ordem). A mesma memória é atualizada em Trois couleurs: bleu, blanc, rouge (1993-1994), a Trilogia das Cores de Krzysztof Kieślowski, uma série de filmes cuja tradução para o português foi feita como "A liberdade é azup", "A igualdade é branca", "A fraternidade é vermelha".
} 
validação em outros espaços de circulação na cidade e é sempre identificado como o estranho (apesar de explicitamente não o parecer, causa do efeito de homogeneidade/inclusão na cidade proporcionada pela ideologia), o conflito não se resolve e continua a se reproduzir.

\section{Considerações finais}

Por fim, para efeito de fechamento, algumas considerações são dignas de nota. Em um plano mais específico, destaca-se que a cidade pode ser tomada como todo significante que se simboliza como lugar discursivo intervalar, abrigando posições-sujeito distintas, em relação a um determinado evento: nesse caso exemplar, a atualização da memória conferida à imigração nos grandes centros urbanos e o consequente acontecimento enunciativo que inaugura essa posição-sujeito de não-abrigado. Na mesma esteira de pensamento, coube à arte a valoração das posições-sujeito imigrantes como positivas, ao deslocar o sentido negativo atribuído ao imigrante e cristalizado pela memória social, interpelando-o como artista, em contraposição ao seu público, e apesar das resistências operadas pelo sujeito. Provém, neste caso, da FD citadina o discurso em que as duas posições em conflito se inscrevem, sem deixar de serem atravessadas pelo lugar da arte, que (também) interpela o sujeito.

No aspecto mais geral, reitera-se a possibilidade de um trabalho de análise sistematizada do texto fílmico, pautada em um arsenal de inspiração semiótica, possibilitada pela arquitetura de um dispositivo que se articula em contato com o linguístico, mas que não se confunde com ele, tido que parte de outro lugar, em diálogo com a Ideologia, a Psicanálise e o Materialismo Histórico. Acrescente-se a isto, o fato de que a complexidade do texto fílmico exige que um tratamento específico seja dado a cada uma das camadas de linguagem que se imbricam e apresentam-se como produto unificado. Cabe, assim, ao analista, o desafio de desmanchar a sequência lógica produzida pela evidência e remontá-la à luz do edifício teórico da Análise de Discurso, que desde a sua fundação manteve o diálogo com outras áreas do conhecimento sem confundir-se com nenhuma delas.

\section{Referências}

CASETTI, Francesco; CHIO, Federico Di. Cómo analizar un film. Barcelona: Ediciones Paidós Ibérica, 1991.

GRIGOLETTO, Evandra. O discurso de divulgação científica: um espaço discursivo intervalar. 2005. Tese (Doutorado em Letras) - Universidade Federal do Rio Grande do Sul, Porto Alegre, 2005.

INDURSKY, Freda. Unicidade, deslocamento, fragmentação: a trajetória da noção de sujeito em Análise do Discurso. In: MITTMANN, Solange; GRIGOLETTTO, Evandra; CAZARIN, Ercília Ana (org.). Práticas discursivas e identitárias: sujeito e língua. Porto Alegre: Nova Prova, 2008.

MARTINS DE SOUZA, Luiz Carlos. Cartas para quem? O funcionamento discursivo da "falta" no filme Central do Brasil. 2012. Tese (Doutorado em Estudos da Linguagem) Universidade Estadual de Campinas, Campinas, 2012.

PÊCHEUX, Michel; FUCHS, Catherine. A propósito da Análise Automática do discurso: atualização e perspectivas. In: GADET, F.; HAK, T. (org.). Por uma análise automática 
do discurso: uma introdução à obra de Michel Pêcheux. Campinas: Unicamp, 1997.

PÊCHEUX, Michel. Papel da memória. In: ACHARD, Pierre et al. (org.) Papel da memória. Campinas: Pontes, 1999.

\section{Canção}

JALOO; MC THA. Letra de Céu Azul. Composição: Jaloo e MC Tha. Genius. Disponível em: https://goo.gl/aNQCWJ. Acesso em: 26 fev. 2019.

\section{Vídeos}

GLOBO. Concertos para a Juventude. Arquivo Memória Globo. Disponível em: https://goo.gl/y1ZRmQ. Acesso em: 26 fev. 2019.

GLOBO. Elis Regina Carvalho Costa. Série Grandes nomes. Arquivo Memória Globo. Disponível em: https://goo.gl/wn4Qru. Acesso em: 26 fev. 2019.

JALOO; MC THA. Céu Azul (Clipe Oficial). Direção de Juily Manghirmalani, Luiz Guilherme Moura e Jaloo, produzido com apoio da São Paulo Film Commission: São Paulo, 2018. Disponível em: https://goo.gl/Z7pxd4. Acesso em: 26 fev. 2019. 